\title{
Pecularities of BIM adoption in Armenia
}

\author{
Marine Ghazaryan * \\ National University of Architecture and Construction of Armenia, Yerevan, Teryan 105, Armenia
}

\begin{abstract}
The progressive penetration of Building Information Modelling (BIM) into the Architecture, Engineering and Construction (AEC) Industry varies in pace and profoundness from country to country depending on level of country development, industry maturity, scale of penetration, willingness of adoption in the institutional and political levels. This article is an attempt to reveal peculiarities and degree of BIM diffusion in developed and developing countries with the focus on case of Armenia. As methods of research was chosen literature review and questionnaire based survey among Industry companies of Armenia. Data collected using interviews and questionnaire surveys among construction and architectural enterprises, managers, owners, NGOs and regulating bodies of AEC industry were analysed. The development directions of the BIM implementation, industry efficiency enhancement issues, BIM related scientific research areas and more were reflected in structured study for Armenia.
\end{abstract}

\section{Introduction}

Building Information Modeling (BIM) as a revolutionary movement progressively penetrates into the Architecture, Engineering and Construction (AEC) Industry making modifications in the working culture, changing local and international protocols and standards, reshaping Industry. Usage of interacting and networking technologies for digital representation of new buildings is being practiced through life span of the construction in a number of developed and developing countries [3,7,10,15,17,18,19,22]. Meanwhile, building information modeling for the existing buildings through laser scanning, photogrammetry and related technologies are also considered to be enabled by BIM [16, 21]. Cloud-based construction project management, visual reality, sensor-based monitoring for measurement of building performances, usage of RFID and a number of other sensor technologies for monitoring are similarly being attributed to BIM technologies $[1,2,5,12]$. So what is BIM? Among several precise and comprehensive definitions of BIM I choose the one from ISO 29481-1:2016 standard that defines BIM as "use of a shared digital representation of a built object (including buildings, bridges, roads, process plants, etc.) to facilitate design, construction and operation processes to form a reliable basis for decisions" [16].

\footnotetext{
*Corresponding author: mghazaryan@nuaca.am
} 
How broadly is digital representation of built objects being shared for construction and operation processes? What are the technical, social and political obstacles hindering BIM adoption? These questions interest AEC Industry worldwide. BIM adoption in wider sense varies from country to country depending on level of country development, Industry maturity, National BIM implementation program, scales of penetration, and willingness of implementation in the institutional and political levels.

\section{BIM in Armenia}

Construction as labor and material intense industry needs continuous efficiency enhancement tools and mechanisms. ICT implementation, industry digitalization and BIM adoption are seen as tools for enhancement of industry efficiency and maintaining sustainability. For assessment of BIM adoption in AEC Industry of Armenia, a research has been carried out and data were collected using interviews and questionnaire surveys among industry enterprises, NGOs and regulating bodies. The aim of the survey was to answer the following questions:

\section{At what extent BIM is being used in Armenian AEC Industry.}

2. Are governmental/regulatory bodies, private $^{2}$ construction and architectural companies, owners, building management organizations and educational institutions aware of BIM and ready for adoption?

3. What are the needed research areas of BIM in Armenia?

4. What is the level of awareness and readiness regarding development and implementation of national BIM implementation program in Armenian AEC Industry?

5. What is the intensity of the use of information and communication technology (ICT) in Armenia's AEC Industry?

\section{Methodology}

The stratified sampling method was selected for the survey where the inclusion criterion for sample selection was the size of the enterprise. Only big and medium enterprises were randomly interviewed and included in the survey as innovative technology adoption assumes substantial financial strength and stability. The field survey was conducted in 2018 February-April and November months in Yerevan, with a randomly selected sample of twenty-eight organizations. The questionnaires were designed to collect exploratory information and quantitative data. It consists of six main parts. The first and second parts of the questionnaire were devoted to identifying the extent of ICT penetration in the internal functional departments of the organization and for the identification of the processes and policies regulating the flow of information between the departments. The third part was dedicated to assess the importance of the BIM adoption on various aspects of national Industry development. The fourth part focuses on identification of needs for the software development, enhancement of the capabilities and skills of young professionals, and ICT's urgent research directions. The fifth part aims to clarify the perception and attribution of BIM, the sixth part, to clarify the most demanding development directions of the BIM from the pre-processed list. At the end, all respondents were given the opportunity to freely express their attitude and thoughts on the subject. The figure below demonstrates distribution of respondents based on their specialization. The majority was construction

\footnotetext{
${ }^{2}$ There are no state owned enterprises in the AEC Industry of Armenia
} 
companies (48\%), descending comes architectural-design enterprises (29\%), owners (5\%), state regulatory bodies, NGOs $(10 \%)$, academia $(5 \%)$, building management organizations $(5 \%)$ that were included in the survey (see Figure 1).

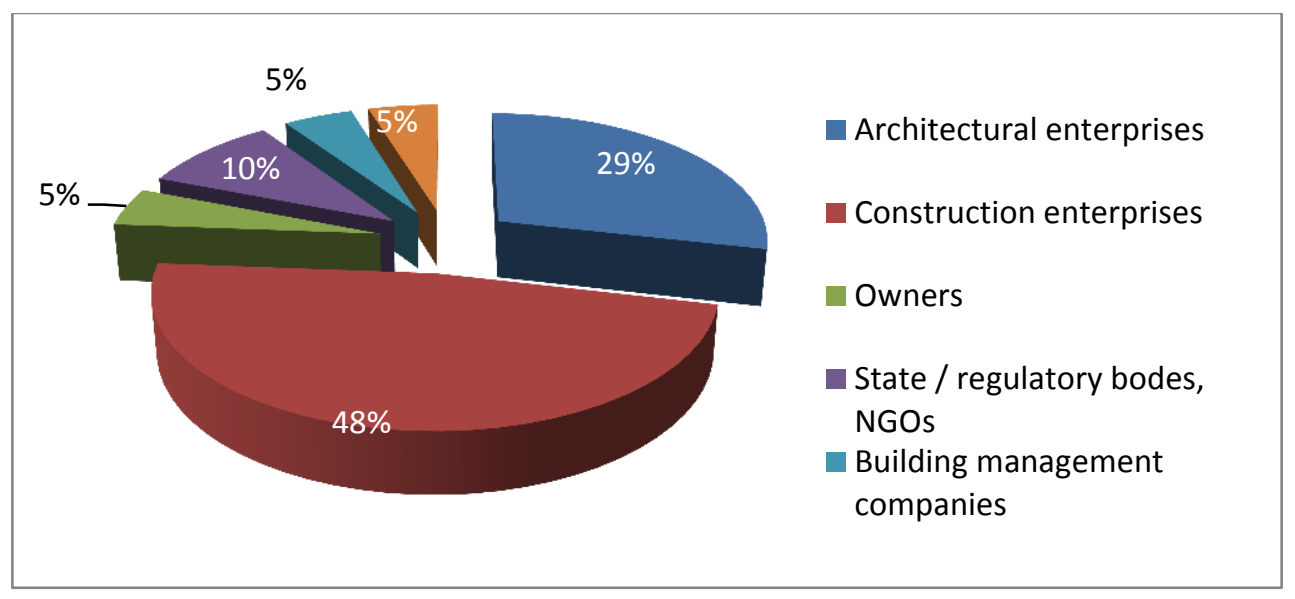

Fig. 1. Respondents' areas of specialization

The importance of BIM adoption was assessed by implementing Relative Importance Index (RII) formula. Five-point assessment system was used for the survey, where 1 is the lowest importance, 5 is the highest importance with the relevant intermediate estimates, less important (2), medium important (3) and important (4). Applied RII formula is:

$$
R I I=\frac{\sum_{i=1}^{k} n_{i} x_{i}}{k \cdot n}
$$

where $\mathrm{k}=5, \mathrm{n}$ is the total number of respondents, $\mathrm{n}_{\mathrm{i}}$ is the number of respondents who chose $\mathrm{x}_{\mathrm{i}}$ criterion appropriate. The result of the formula lies in range from 0 to 1 . Where RII $<0.60$ shows the low importance, the values in the range $0.60 \leq \mathrm{RII}<0.80$ are of moderate importance and RII $\geq 0.80$ are of high importance [13].

\section{Outcome}

From the table below, we see that for the organizations operating in the Republic of Armenia (RA) AEC Industry, adoption of BIM is highly valued for the architectural and design works; cost estimation and budgeting; time management; work efficiency enhancement and construction project management. Moderate importance was attributed to work safety, security and building life cycle management. The use of BIM during technical and architectural supervision, and demolition at the end of life cycle was considered of low importance. 
Table 1. Importance of BIM adoption by areas

\begin{tabular}{|l|c|c|}
\hline \multicolumn{1}{|c|}{ Areas } & RII & Rating \\
\hline Architectural and design works & 0.99 & 1 \\
\hline Cost estimation and budgeting & 0.96 & 2 \\
\hline Time management and saving & 0.89 & 3 \\
\hline Work efficiency enhancement & 0.86 & 4 \\
\hline Resource savings & 0.83 & 5 \\
\hline Construction project management & 0.74 & 6 \\
\hline Work safety and security management & 0.67 & 7 \\
\hline Building life cycle management & 0.66 & 8 \\
\hline $\begin{array}{l}\text { Technical supervision and architectural } \\
\text { supervision }\end{array}$ & 0.47 & 9 \\
\hline Demolition and deconstruction & 0.21 & 10 \\
\hline
\end{tabular}

The rating of the scientific research and development directions for BIM is presented in the Table 2 and demonstrates unity of all respondents participated in the survey. All of them highly value (1) development of mobile technology applications for BIM, (2) importance of BIM diffusion for Sustainable Development, (3) quantity survey and cost control technologies based on normative elements and market, (4) sensor-based monitoring and measurement technologies implementations, (5) visual reality executions and at the end (6) cloud-based project management development.

Table 2. Rating of scientific and research directions

\begin{tabular}{|l|l|l|}
\hline \multicolumn{1}{|c|}{ Topics } & RII & Rating \\
\hline mobile technologies & 0.97 & 1 \\
\hline sustainable development & 0.96 & 2 \\
\hline cost estimation & 0.96 & 3 \\
\hline $\begin{array}{l}\text { sensor-based tracking and } \\
\text { measurement }\end{array}$ & 0.93 & 4 \\
\hline visual reality & 0.84 & 5 \\
\hline cloud based project management & 0.71 & 6 \\
\hline
\end{tabular}

To the question, what are the needed research areas of BIM in Armenia, the following research topics were considered as top priority:

- Organization and implementation of the automated monitoring systems for maintenance of seismic safety of buildings and structures.

- Enhancement of the role of ICT in building energy efficiency management.

$74 \%$ of survey participant rated of high importance existence of National BIM Implementation Program. The survey reveals that it is highly valued by the owners and state regulatory bodies, close to moderate valued by the architectural companies and rated of a low value by the construction companies. The rate of the property managers is close to 0 as the institute of the property management is underdeveloped in RA. (Figure 2) 


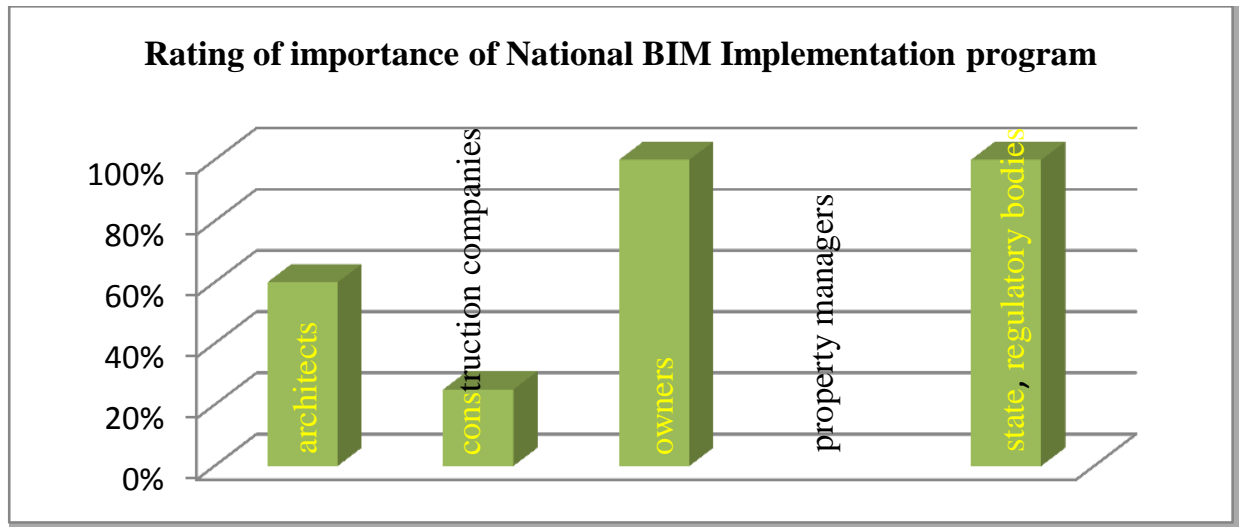

Fig. 2. Rating of importance on National BIM implementation program

For the assessment of BIM utilization a list of 175 software were ranked by the respondents. According to this study the most frequently used BIM software in RA is AutoCAD with the 0.86 Relative Importance Index. The second most frequently used software is ArchiCAD with the 0.33 RII. Only 20 out of 175 software have above zero RII (the list is presented on Table 3). The justification for this limited utilization of BIM software is lack of larger, more complex, commercial, residential and infrastructural construction projects $[4,20]$ with BIM applications. BIM software variety and application possibilities are not recognized due to low awareness and knowledge gap. In addition there are limited studies conducted in RA on BIM awareness level in particular and BIM adoption in general.

Table 3. BIM software Relative Index

\begin{tabular}{|l|l|}
\hline & RII \\
\hline AutoCAD & 0.857 \\
\hline ARCHICAD & 0.329 \\
\hline Sketchup & 0.214 \\
\hline 3ds Max & 0.143 \\
\hline AutoCAD Civil 3D & 0.143 \\
\hline Revit Architecture & 0.143 \\
\hline Tekla Structures & 0.143 \\
\hline LIRA & 0.143 \\
\hline V-RAY & 0.143 \\
\hline AutoCAD Map 3D & 0.129 \\
\hline ReCap Products & 0.114 \\
\hline AutoCAD 360 & 0.071 \\
\hline Navisworks & 0.071 \\
\hline Revit MEP & 0.071 \\
\hline BIM 360 Products & 0.057 \\
\hline Energy Analysis for Autodesk Revit & 0.057 \\
\hline Rhino & 0.057 \\
\hline Grasshopper & 0.057 \\
\hline Trimble SketchUp & 0.043 \\
\hline Revit Structure & 0.029 \\
\hline
\end{tabular}




\section{Conclusion}

While BIM is not a new concept, its diffusion in RA construction industry is very slow. The survey reveals that importance and need for the development and implementation of a national BIM implementation program is widely recognized by state regulatory bodies and owner. BIM adoption is becoming an increasingly important factor for the Industry efficiency enhancement and gaining international competitiveness for RA AEC industry. New technologies bring profound changes in the processes of the involved parties, working culture, national regional and international protocols and standards. Advantages of using BIM in new private and state owned construction projects are proven by the involved parties internationally $[6,8,9,14]$. The main advantages are interaction of architectural design and construction visualization, automated cost estimation and cost control, clash detection, time and cost saving, and improved collaboration of the involved parties. The main problems facing BIM implementation in newly constructed buildings are linked to scarcity of BIM professionals and knowledge required for the implementation of integrated construction project delivery. Adoption of BIM requires new skills, knowledge, and awareness.

This paper was supported by the Thematic Funding Program of the State Scientific Committee of RA. The research was conducted for "Development of Automated Work Station (Office) for Architectural, Construction and Engineering Works" project. I would like to thank all the participants of the survey for their support and contribution.

\section{References}

1. Akinci B, Boukamp F, Gordon C, Huber D, Lyons C, Park K. A formalism for utilization of sensor systems and integrated project models for active construction quality control. Automation in Construction 2006;15:124-38.

2. Becerik-Gerber B, Jazizadeh F, Li N, Calis G. Application areas and data requirements for BIM-enabled facilities management. Journal of Construction Engineering and Management 2012;138:431-42

3. Becerik-Gerber B, Rice S. The perceived value of building information modeling in the U.S. building industry. ITcon 2010;15:185-201.

4. Becerik-Gerber B, Rice $\mathrm{S}$. The perceived value of building information modeling in the U.S. building industry. ITcon 2010;15:185-201.

5. Costin, Pradhananga, Teizer. Leveraging passive RFID technology for construction resource, field mobility and status monitoring in a high-rise renovation project. Automation in Construction 2012;24:1-15.

6. Eastman, Teicholz, Sacks, Liston. BIM Handbook - A Guide to Building Information Modeling for Owners, Managers, Designers, Engineers and Contractors. 2. Aufl. Hoboken: Wiley; 2011.

7. Gray M, Grey J, Teo M, Chi S "Building Information Modeling: An International Survey", Bishbane, Australia, 2013

8. Gray M, Gray J, Teo M, Chi S, Cheung F. Building Information Modeling: An International survey, Brisbane, Australia: 2013.

9. $\mathrm{Gu} \mathrm{N}$, London $\mathrm{K}$. Understanding and facilitating BIM adoption in the AEC industry. Automation in Construction 2010;19:988-99.

10. Hosseini R, Azari E, Tivendale L, Chileshe N, "Barriers to adoption of building information modeling (BIM) in Iran: Preliminary results", 2015, 384-394

11. ISO Standard. ISO29481-1:2016 Building Information Modeling -Information Delivery Manual-Part1 Methodology and format, 2016 
12. Jehle P, Seyffert S, Wagner S, Michailenko N. Das intelligente Bauteil im integrierten Gebäudemodell - Pilotprojekt zur Anwendung der RFID-Technologie in Bauteilen. 1. Aufl. Wiesbaden: Vieweg+Teubner Research; 2011.

13. Kado. D., \& Avul. T. M., (2010). The Influence of Construction Supervisors' Training on Rework, Construction Focus, Vol 3, No 1, pp 35-48.

14. Krygiel E, Nies B. Green BIM: successful sustainable design with building information modeling. Indianapolis, Indiana: Wiley Publishing; 2008.

15. Maria Joao Silva, Fillipa Salvado, Paula Couto, Alvaro Vale e Azevedo."Roadmap Proposal for Implementing Building Information Modeling (BIM) in Portugal", Open Journal of Civil Engineering, 2016, vol. 6

16. Mill T, Alt A, Liias R. Combined 3D building surveying techniques - terrestrial laser scanning (TLS) and total station surveying for BIM data management purposes. Journal of Civil Engineering and Management 2013;iFirst 1-10, Published online: 24 Oct 2013.

17. Nanajkar A, Gao Z "BIM Implementation Practices at India's AEC Firms", Kunming, China, 2014

18. National Building Information Modelling Initiative (NBI), BEIIC (the Built Environment Industry Innovation Council), Australia, 2012.

19. Penttila H, Rajala M, Freese S Building Information Modeling of Modern Historic Buildings. 607-613, 2007

20. RICS. RICS BIM survey results. The Royal Institute of Charted Surveyors; 2013.

21. Tang P, Huber D, Akinci B, Lipman R, Lytle A. Automatic reconstruction of as-built building information models from laser-scanned point clouds: A review of related techniques. Automation in Construction 2010;19:829-43.

22. Wong A, Wong F "Comperative Roles of Major Stakeholders for the Implementation of BIM 